regional planning as a basis for the reconstruction and expansion of the national economy; and Dziewonski's paper shows that the methods and results of geographical research in Poland have exerted very considerable influence on the methods and results of planning. For this there is not, and probably never will be, any exact British parallel, but Polish experience does heavily underline the diversity of the ways in which the work of geographers can be used for the nation's good, if they are given the opportunity and the encouragement.

International seminars of this type broaden the minds of those participating and at the same time help to create deeper understanding and friendship, while the circulation of the report of the proceedings will be of lasting value to all who are interested in applied geography and who are concerned that it should have the closest possible connexion with life and society. Robert W. STEEL

${ }^{1}$ The map prepared by the Ministry of Housing and Local Government is being published by H.M. Stationery Offee.

"Technology and Geography", to appear in The Advancement of

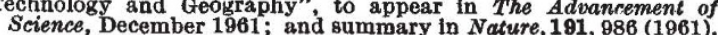
s Stamp, L. Dudley, Applied Geography (1960).

"See especially Stamp, L. Dudley, The Land of Britain: Its Use and Misuse (1948).

${ }^{6}$ Report of the Committee on Land Vtilisation in Rural Areas (Cmd. 6378) (H.M.S.O., London, 1942).

- Four of the World Land Use Survey's reportz have so far been published, the most recent being Niddrie, D. L.; Land Use and
Population in Tobago (Geographical Publications, Bude, 1961).

' Problems of Applied Geography, Geographical Studies No. 25, Polish Academy of Sciences, Institute of Geography (Warzzawa, Copies (price 258.) can be obtalned from the treasurer of the Institute of British Geographers, Dr. H. C. K. Henderson, Birkbeck College, Malet Street, London, W.C.i.

${ }^{8}$ See Hartshorne, R., "The American-Polish Geographical Seminar and Excursion, 1960", Geog. Rev., 61, 443 (1961).

\title{
GAS CHROMATOGRAPHY IN MEDICAL RESEARCH
}

$\mathrm{T}$ HE Gas Chromatography Discussion Group of the Institute of Petroleum held an informal symposium on September 26, at the Royal College of Surgeons of England in London.

In welcoming the members of the Group, Prof. R. F. Woolmer, on behalf of the President and Council, explained that, apart from surgery, the College research and teaching also covered such associated fields as physiology, biochemistry, dental science and anæsthetics. It was appropriate that a symposium concerned mainly with the aspects of gas chromatography in medical research should be held at the College, as they believed in co-operation and a full exchange of ideas with other workers.

In the opening paper, Dr. A. T. James described the development and operation of a simple detector for the continuous automatic determination of the radioactivity of carbon- 14 and tritium. Attention had been directed to automatic determination because of the obvious disadvantages of the previously used discontinuous methods. Problems of stability at column temperatures as high as $200^{\circ} \mathrm{C}$. had led to combustion of the eluted material to carbon dioxide and water, and the measurement of the radioactivity at room temperature. The detector consisted of a $4 \times \frac{1}{2}$ in. copper tube, plated internally and having a central tungsten wire electrode. Rhodium plating reduced the tailing exhibited by tritiated materials. Argon or helium was used as carrier gas, and carbon dioxide was bled into the feed to the detector to give a concentration of approximately 5 per cent. Chromatograms obtained with conventional detectors and the radioactivity detector were shown to superimpose extremely well. An integrated record could also be produced.

The next paper, on gas-liquid radiochromatography, by Dr. S. Popják, confirmed the disadvantages of discontinuous procedures for radioactivity measure. ments. The advantages of continuous monitoring over fraction collection had been evident over a period. of three years using a scintillation counter. In the method described, carrier gas and eluted fractions were passed through a liquid scintillator in a specially designed apparatus, and the radioactivity measured by scintillation counting. Two isotopes could be messured simultaneously. Full details of the construction of the apparatus, its method of operation and the associated electronic circuitry were given. A stepped record superimposed well on chromatograms obtained with a gas density balance. The efficiency of counting was of the order of 40-50 per cent for carbon-14 compounds, and 15-21 per cent for tritiated compounds.

Under the title of "Peak Symmetry in Gas-Solid Chromatography", Mr. C. G. Scott described recent work concerned with the properties of two active solid systems giving symmetrical elution peaks for hydrocarbons at column temperatures below the boiling point of the eluted component. When alumina is modified with sodium hydroxide, the energy of adsorption decreases to a constant value, at which stage symmetrical elution peaks are obtained. Such peaks can also be obtained from columns packed with solid organic crystals, although, to increase surface area and so reduce column lengths, the compounds are best deposited on 'Celite'. It had been found that heats of adsorption were of the same numerical magnitude as the heats of vaporization. Entropies of adsorption were calculated for $n$-heptane, benzene, iso-octane and cyclohexane, and values obtained for the first two compared with those obtained by Kemball for adsorption on mercury.

Mr. D. W. Hill and Dr. R. P. W. Scott described recent developments in the design of compact cathoderay tube gas chromatographs. Apart from the high speed of analysis for vapours containing anæsthetics, the apparatus should be compact for easy transport and use in an operating theatre, and be capable of giving rapid repetitive results. The instrument was designed around a 6-in. square, long-persistence tube having a 20-30 sec. scan, and contained its own pump. An additional port in the sample injection system allowed a $100: 1$ gas dilution without the high losses of argon given by 'splitter systems'. The micro argon detector had been modified to reduce the effects of electron capture so that the strongly electron-capturing halothane (2-bromo-2-chloro-1,1,1-trifluoroethane) gave a positive peak. Column packings for the separation of typical anæesthetic mixtures were mentioned. The quantitative response of the argon detector was dependent on temperature, and therefore the use of a thermostat or compensation was necessary. A simple thermistor compensator unit was described. 
Dr. R. A. Butler presented a paper entitled "Parts Per Million and All 'That" in which he first described his work on anæsthetics, indicating the importance of knowing the concentration of anæsthetics in tissue, the rate of its elimination from the tissue, and equilibrium values of the various substences used. He queried the accuracy of calibration standards made from volatile substances, and consequently the accuracy of a detector calibration using such standards. He felt that some absolute figures often quoted in papers were at the least rather optimistic, and his paper was obviously designed to stimulate a discussion on the quantitative aspects of gas chromatography. It was unfortunate and disappointing that it failed to do so.

A contribution by Dr. T. R. Phillips deseribed how, during the analysis of Arcton 12 (dichlorodiffuoromethane) in Arcton 11 (monochlorotriffuoromethane), the calibration of the apparatus had to be carried out with synthetic mixtures of the substances and the samples taken at a fixed pressure. The sensitivity of the apparatus for Arcton 12 expressed as peak. height/partial pressure was shown to vary with the total pressure of the sample and with the partial pressure of Arcton 11. It was thought that this effect could occur in other systems where a small amount of a weakly retained substance was being analysed in the presence of excess of a more strongly retained one. Dr. Phillips's suggestion that the effect would not be observed if integration of the peak were used instead of the measurement of peak height was confirmed by other contributors to the discussion.

The concluding paper on electron capture was given by Mr. N. L. Gregory. He described a detector to which a potential of only 10-20 V. was applied and which utilized recombination effects to measure compounds having an affinity for free electrons. It was extremely sensitive to halogenated compounds, a typical application being to the detection and determination of insecticides in foodstuffs. Another application was to the determination of tetraethyl lead in gasoline, there being no response to the hydrocarbons present. Apart from halogenated compounds, polycyclic aromatic hydrocarbons, unsaturated fatty-acid esters and quinones were also good electron acceptors. The possibility of the affinity of organic compounds for free electrons in biochemical processes was mentioned.

Members of the Group were also privileged to view apparatus, watch demonstrations, and discuss gas chromatographic techniques with workers in various departments of the College, and also in the adjoining Nuffield College of Surgical Sciences. This was much appreciated by those present.

C. E. H. KNAPMAN

\section{INDUSTRIAL TRAINING IN EUROPE}

CPEAKERS from Belgium, Holland, Sweden and Switzerland joined colleagues from Britain at the annual conference of the British Association for Commerical and Industrial Education which was held at the University of Nottingham during September 14-16, when an examination was made of education and training on the continent of Europe, with particular reference to the effects of economic integration. The theme of the conference is of special significance since free movement of labour among Common Market countries may lead to standardization of systems of education and training, or at least a levelling up of standards.

One common thread ran through all the papers - the need to direct more attention to general education in modorn schemes of training. All the countries present are now beginning to examine their training systems from this point of view.

Among the contributors were Monsieur R. Grandbois, inspector-general of the French Ministry of Education, who stated that all differences concerning apprenticeships are a consequence of the past. They are the result of local habits and customs; they represent the embodiment of a way of life, the outcome of an evolution both social and administrative. All the similarities are either a consequence of the present or a result of the pressure of things to come. The various systems of apprenticeship have evolved slowly to their present-day form and crystallized behind innumerable frontiers and in confined surroundings, but they are now and will henceforth be subjected to influences for which barriers and remote. ness do not exist. It can be assumed that the apprentices of to-morrow will have to be educated in much the same way whatever the country to which they belong.

Monsieur G. C. M. Hardebeck, secretary of the Bemetal Foundation in Holland, believes that more attention must be directed to general education because it is our responsibility not only to give young people the necessary technical training but also to prepare them to live in a democracy.

In his paper, Mr. H. A. Warren, principal of the South-East London Technical College, explained how in Great Britain at a time in the 1930's, when thousands of man-hours were being idled away in unemployment, the young apprentice was asked to work 48 hours a week and in addition, three evenings at college and two more on homework. A fow million pounds extra expenditure on day release at that time would have meant that Britain to-day would no longer be suffering from a lack of skilled man-power. Warren suggested that the wholly evening course, except for recreation or for advanced refresher course studies, is as out of date as the steam locomotive; despite this, Britain has the administrative arrangements which, to meet the challenge of the changing nature of skill, stand out as far superior to anything in continental Europe. "Nowhere in Western Europe is the sandwich course at the C.A.T. [college of advanced technology $\rceil$ level and standard growing to full and recognized stature as it is in Britain".

The pattern of industrial education might have been greatly strengthened had the City and Guilds of London Institute been entrusted also with the General Certificate course at least up to the Ordinary Level of the General Certificate of Education.

The British system is weak because of its lack of incentive. Since no end-of-apprenticeship tests are insisted on, the studies for apprentices in a technical college are voluntary both in the sense of attendance, and in the sense of aoquiring a qualification. When, in addition, little recognition will accrue in wages or promotion, the student not unreasonably asks himself why he is pursuing his studies. 